\title{
Study on Eco-efficiency Assessment of Jiangxi in China Based on Data Envelopment Analysis
}

\author{
Mianhao Hu ${ }^{1}$, Hengyu You ${ }^{2}$, Jiang Tong ${ }^{3}$, Jiayi Wang ${ }^{2}$, Zaohong Zhou ${ }^{1,2, ~ * ~}$ \\ ${ }^{1}$ Institute of Poyang Lake Eco-economics, Jiangxi University of Finance \& Economics, Nanchang, Jiangxi, P. R. China \\ ${ }^{2}$ School of Tourism and Urban Management, Jiangxi University of Finance \& Economics, Nanchang, Jiangxi, P. R. China \\ ${ }^{3}$ School of Statistics, Jiangxi University of Finance \& Economics, Nanchang, Jiangxi, P. R. China
}

\section{Email address:}

397419494@qq.com (Mianhao Hu),1064234964@qq.com (Hengyu You), star.fruit.poetry@qq.com (Jiang Tong), 411839472@qq.com (Jiayi Wang), zhzhou3995@126.com (Zaohong Zhou)

\section{To cite this article:}

Mianhao Hu, Hengyu You, Jiang Tong, Jiayi Wang, Zaohong Zhou. Study on Eco-efficiency Assessment of Jiangxi in China Based on Data Envelopment Analysis. Science Journal of Business and Management. Vol. 4, No. 1, 2016, pp. 8-16. doi: 10.11648/j.sjbm.20160401.12

\begin{abstract}
Currently, the strengthening of regional Eco-efficiency research is imperative. This paper establishes the appropriate ecological efficiency evaluation index system by drawing on the research on the ecological efficiency of domestic and foreign scholars. First, evaluate the Eco-efficiency of 11 cities in Jiangxi Province by using DEA method. Then we use SE-DEA to sort the regional that ecological efficiency is equal to 1. Finally, using Malmquist dynamic index to analyze the eco efficiency of each region, and achieve the purpose that study on Evaluation of regional ecological efficiency. The research shows that in the study period, the ecological efficiency of the regional level of Jiangxi province is relatively low, there is no obvious difference between the ecological efficiency of each region, and the growth rate in a downward trend. Each city in the redundant input indexes vary greatly, mainly in four aspects, including the total water consumption, employees, investment in fixed assets and wastewater discharge. Therefore, Jiangxi province should actively change the mode of economic development, strengthen regional cooperation to improve the utilization of resources, actively guide foreign investment, increase investment in education, strengthen the management of environmental pollution, improve environmental governance capacity.
\end{abstract}

Keywords: Area, Eco-efficiency, DEA, Jiangxi Province

\section{Introduction}

Today, the conflict between economic development and environmental protection increasingly prominent in the world, in order to achieve sustainable human development, there is growing emphasis on Eco-efficiency. In 1990, German scholar Schaltegger [1] first proposed the concept of ecological efficiency, and considered that the "eco efficiency" can more consider the environmental impact of economic activities. Currently, the universally recognized "Eco-efficiency" is defined by the 1992 World Sustainable Development Industry and Commerce Commission (WBCSD): Eco-efficiency is achieved by providing energy to meet human needs and improve the quality of life of competitive pricing of goods and services, while the ecological impacts and resource intensity throughout the life cycle is gradually reduced to a least consistent with the estimated carrying capacity of the planet level [2].

Eco-efficiency concept is proposed based on the industry level, the current research on Eco-efficiency are mostly based on the industrial park or a particular industry, a qualitative study of the industry [3-5], The quantitative study on the measurement and evaluation of ecological efficiency is rare [6], and the research of the regional macro level is only just begun [7], and it is less in the area of regional space-time. Therefore, it is necessary to strengthen the study of regional eco efficiency. In China, Jiangxi province is located in the lower reaches of Yangtze River, it has an area of 166,900 square kilometers and a population of 45.22 million. Jiangxi is a typical inland province, traffic is convenient, it has some ecological advantages. But the economy is not developed, which belongs to the typical extensive development, the overall level is not high. Therefore, we take Jiangxi Province as an example, research the regional ecological benefit. On the one hand, the study has the important practical significance, but also have sufficient theoretical guidance for underdeveloped areas, and provide a good reference for economic and social development in underdeveloped areas. This paper will provide reasonable suggestions for regional 
development, improve the competitiveness of the region through the comparison of 11 cities in Jiangxi Province.

\section{Regional Eco-efficiency Evaluation}

\subsection{Index Selection and Data Sources}

The concept of Eco-efficiency means that the system uses less resources and environmental costs to get more economic benefits, the core idea is "less investment and more output". It is a country or region of the important embodiment of the green competitiveness, its model expression as (1) type is shown: [8]

\section{$\mathrm{EE}=\mathrm{VPS} / \mathrm{IPM}$}

Note: "EE" indicates Ecological efficiency; "VPS" indicates The value of a product or service; "IPM" indicates Impact of pollutant discharge or material consumption

From the above equation, the Eco-efficiency indicators include input index and output index. Input index include not only all the necessary resources for economic activity, such as natural resources or labor resources, but also includes a variety of waste generated in the process of economic operation, such as waste water, as well as a variety of solid waste. Usually used gross domestic product (Value) as the output items.

At present, there is no uniform standard for the choice of the input index and output index. Through the literature research, in foreign countries, the representative research mainly is the index proposed by BijiKurup [9-13], as shown in Table 1; at the same time, in China the representative research mainly is the index of Jingru Liu [14-20] and other scholars, as shown in table 2.

Table 1. Evaluation index of foreign scholars.

\begin{tabular}{|c|c|}
\hline Representative Figures & Evaluation Index \\
\hline BijiKurup & $\begin{array}{l}\text { Static Environmental Benefits; Natural resources; Water Quality; Air quality; biodiversity } \\
\text { Dynamic environmental benefits; Consumption and use efficiency on energy, water, raw materials; the situation of Emissions } \\
\text { and land cleanup }\end{array}$ \\
\hline Helge Bratteb & $\begin{array}{l}\text { Mass production capacity; utilization of renewable; Energy prices; Transportation costs; Waste discharge costs; Secondary raw } \\
\text { material quality standard }\end{array}$ \\
\hline Michelsen & $\begin{array}{l}\text { Energy consumption; material consumption; emissions of ozone-depleting gases; Water consumption; greenhouse gas } \\
\text { emissions; emissions of acid gases in the atmosphere; Total waste generation; photochemical smog gas generation; heavy metal } \\
\text { emissions }\end{array}$ \\
\hline Trondheim & Ecological Evaluation; recycling rate; recovery rate and total regeneration rate \\
\hline Van Caneghem & Volatile acid; oxidant; human toxicity; Fresh water aquatic toxicity \\
\hline
\end{tabular}

Table 2. Evaluation index of Chinese scholars.

\begin{tabular}{|c|c|}
\hline Representative Figures & Evaluation Index \\
\hline Chaona $\mathrm{Li}$ & $\begin{array}{l}\text { Ecological environment quality index; Pollution reduction targets; Resource consumption intensity index; Characteristics of eco } \\
\text { industrial park and park management }\end{array}$ \\
\hline Jingru Liu & Three main functions of social, economic and natural; three subsystems of production, life and ecological system \\
\hline Lin Ma & $\begin{array}{l}\text { Renewable resources; water recycling rate; industrial wastewater compliance rate; Industrial dust; industrial sulfur dioxide; } \\
\text { industrial solid waste comprehensive utilization rate; industrial park green rate }\end{array}$ \\
\hline Na Zhang & Construction of ecological efficiency evaluation index system from three aspects: structure, function, process indicators \\
\hline Jiating Wang & Economic development; recycling; environmental protection and green management \\
\hline Chanjuan Xiao & Eco efficiency of industrial wastewater; Eco efficiency of industrial waste gas; Eco efficiency of industrial solid waste \\
\hline Xiaomei Sun & $\begin{array}{l}\text { Economic efficiency; Resource conversion efficiency; Pollution reduction efficiency; Eco industrial characteristics and } \\
\text { management efficiency of the park }\end{array}$ \\
\hline
\end{tabular}

In order to make the evaluation index system more reasonable, taking into account the availability of information, through the study of the domestic and foreign researchers' indicators, the evaluation index system of eco efficiency is established, which is shown in Table 3.

Table 3. Evaluation index of regional ecological efficiency.

\begin{tabular}{llll}
\hline index & Category & Specific index form & Contents \\
\hline & & Fresh water consumption & Total amount of water \\
& \multirow{2}{*}{ Resource consumption } & Land resource consumption & Construction land area \\
Input index & & Human resource consumption & Number of employees \\
& & Fixed asset investment & Fixed asset investment \\
& & Wastewater discharge & Wastewater discharge \\
& \multirow{2}{*}{ Environmental impact } & Waste gas discharge & Emissions \\
& & Solid waste discharge & Solid wastes \\
& & Economic aggregate & Gross national product \\
\hline
\end{tabular}

In Table 3, the input indicators include index of resource consumption and environmental impact index. Because regional production activities not only to consume the resources, but also produce a series of waste, This is also as the production of environmental consumption. Specific index have the following 5:

(1) the total amount of water. This index refers to the total amount of water used in the region, not only for 
industrial water use, but also for water consumption and water consumption for agriculture.

(2) Construction land area. This index refers to the area within the various types of land area, the choice of the index is to evaluate the efficiency of land use.

(3) Number of employees. This index refers to the number of employees in the region, which is an important resource in economic development, we cannot ignore the role of artificial.

(4) Fixed asset investment. This index is the monetary investment in the region or the related industry in a certain period of time, which can reflect the scale of investment and the effect of monetary investment.

(5) The "three wastes" index. These index are an indispensable part of the input index, because the ecological efficiency evaluation should take the impact of the environment into account, which is indispensable to the impact of pollutants on the environment.

Output indicator is the national product, The indicator shows the final outcome of the industrial production activities through the monetary form, The capital efficiency and the efficiency of the raw materials are not recorded in the study areas [6].

Basic data mainly comes from the Jiangxi statistical yearbook 2010-2014.

\subsection{Research Methods}

Envelopment Analysis Data (DEA) is the first proposed by Charnes [21] in 1978. This method mainly uses linear programming method, each units being evaluated (area, department, or year) is used as a Decision Making Units (DMU) by observing the effective sample data. Then, the effectiveness of the decision making unit is evaluated, and the results show that the relative efficiency of each decision unit. At the same time, the so-called decision making unit is a system which can produce products and services as long as the input of production factors. In the evaluation of a certain number of decision making units, the input and output relationship of each unit should be evaluated, then see whether it is reasonable. This method uses linear programming to deal with the large number of inputs and outputs, and evaluate the effectiveness of those objects that can be compared, obviously those systems with complex inputs and outputs can take this approach. The advantage is that the amount of data is not high, which can ensure that the evaluation results are less affected by other factors, but also to maintain a high sensitivity. Compared with other evaluation models, the biggest advantage of the data envelopment analysis is the determination of the weight, most of the other methods need to rely on the subjective attitude to determine the weight of index, which will inevitably be influenced by the subjective factors, and the data envelopment analysis will avoid this charge. Because the data envelopment analysis can evaluate the relative efficiency of similar units, this will make it work in comparative analysis, which can not only satisfy the characteristics of multiple input and output indicators, but also do not need to carry out any of the functions of the variables.

\subsection{1. $C^{2} R$ Model}

If there are $\mathrm{n}$ decision making units, each decision-making unit has $\mathrm{m}$ input and $\mathrm{s}$ output, input and output have different economic indicators to replace, this evaluation model consists of multiple inputs and multiple outputs. $X_{j}$ is used to represent the input, output represented by $\mathrm{Y}_{\mathrm{j}}$.

$$
\begin{gathered}
X_{j}=\left(x_{1 j}, x_{2 j}, \ldots, x_{m j}\right)^{T} \\
Y_{j}=\left(y_{1 j}, y_{2 j}, \ldots, y_{m j}\right)^{T}, j=1,2, \ldots n .
\end{gathered}
$$

Evaluation of the effectiveness of the $\mathrm{j}$ decision making unit, $\mathrm{C}^{2} \mathrm{R}$ model proposed by Charnes [21] is as follows:

$$
\left\{\begin{array}{c}
\min \theta=V_{D} \\
\text { s.t. } \sum_{j=1}^{n} \lambda_{j} X_{j}+S^{-}=\theta X_{0} \\
\sum_{j=1}^{n} \lambda_{j} Y_{j}-S^{+}=Y_{0} \\
\lambda_{j} \geq 0, j=1,2, \cdots, n \\
S^{-} \geq 0 \\
S^{+} \geq 0
\end{array}\right.
$$

In the above formula, $X_{j}, Y_{j}$ respectively, the input and output indicators, $\lambda_{\mathrm{j}}$ denotes a unit combination coefficients. $\theta$, $\mathrm{S}^{-}, \mathrm{S}^{+}$as the criterion for evaluating relative effectiveness of decision making units, $\theta$ is represented by relative efficiency value calculated by the model, $\mathrm{S}^{+}, \mathrm{S}^{-}$is the slack variable.

When the $\theta$ value of 1 , indicating weak DEA effective decision-making unit; if $\theta$ is 1 , and $\mathrm{s}^{-0}=\mathrm{s}^{+0}=0$, then the decision unit effective for the DEA. If $\theta$ less than 1 , and $\mathrm{S}^{-}, \mathrm{S}^{+}$ is not all 0 , it is considered that the evaluation of DMU is invalid DEA.

\subsubsection{BC Model $^{2}$}

In 1993 P. Anersen and other scholars put forward the $\mathrm{BC}^{2}$ model. Based on the $\mathrm{C}^{2} \mathrm{R}$ model, it is possible to make a further evaluation and comparison of multiple main bodies, but which can not be further evaluated and compared. So the improved model of $\mathrm{C}^{2} \mathrm{R}$ model, namely $\mathrm{BC}^{2}$ model (DEA model) [22], is proposed.

$$
\left\{\begin{array}{c}
\min \left[\theta-\varepsilon\left(\sum_{j=1}^{m} S_{j}^{-}+\sum_{j=1}^{m} S_{j}^{+}\right)=V_{D}(\varepsilon)\right. \\
\text { s.t. } \sum_{j=1}^{n} \lambda_{j} X_{j}+S^{-} \leq \theta X_{0} \\
\sum_{j=1}^{n} \lambda_{j} Y_{j}-S^{+}=Y_{0} \\
\lambda_{j} \geq 0, j=1,2, \cdots, n \\
S^{-} \geq 0 \\
S^{+} \geq 0
\end{array}\right.
$$

In the formula, the $\varepsilon$ is Archimedes infinity, and the rest of the meaning is the same as (3).

The evaluation of the super efficiency DEA model is as follows: In the evaluation, the decision making unit is invalid, and the production frontier will not change; But in the 
effective decision-making unit, under the premise that the efficiency value is invariable, the ratio of the input to the increase of the input is recorded as the super efficiency evaluation value.

\subsubsection{Malmquist Index}

Malmquist productivity index was first proposed by Sten Malmquist in 1953, Subsequently, Fare, Grosskopf and other

$$
T P F=\left[\frac{D_{\left(x_{t+1}, y_{t+1}\right)}^{t}}{D_{\left(x_{t}, y_{t}\right)}^{t}} \times \frac{D_{\left(x_{t+1}, y_{t+1}\right)}^{t+1}}{D_{\left(x_{t}, y_{t}\right)}^{t+1}}\right]^{\frac{1}{2}}=\frac{D_{\left(x_{t+1}, y_{t+1}\right)}^{t+1}}{D_{\left(x_{t}, y_{t}\right)}^{t}} \times\left[\frac{D_{\left(x_{t+1}, y_{t+1}\right)}^{t}}{D_{\left(x_{t+1}, y_{t+1}\right)}^{t+1}} \times \frac{D_{\left(x_{t}, y_{t}\right)}^{t}}{D_{\left(x_{t}, y_{t}\right)}^{t+1}}\right]^{\frac{1}{2}}
$$

Malmquist production index can also be expressed as TPF, which means that a decision unit in the $\mathrm{T}$ to $\mathrm{t}+1$ period of the degree of productivity change. If $\mathrm{TPF}>1$, the yield is increased, in turn, indicates declining trend. Because TPF can be decomposed into technical change (TC) and efficiency change (EC). $\left[\frac{D_{\left(x_{t+1}, y_{t+1}\right)}^{t}}{D_{\left(x_{t+1}, y_{t+1}\right)}^{t+1}} \times \frac{D_{\left(x_{t}, y_{t}\right)}^{t}}{D_{\left(x_{t}, y_{t}\right)}^{t+1}}\right]^{\frac{1}{2}}$ in the formula (5) is a technical change (TC), that is, the contribution of the mobile to the productivity of the production frontier, $\frac{D_{\left(x_{t+1}, y_{t+1}\right)}^{t+1}}{D_{\left(x_{t}, y_{t}\right)}^{t}}$ is the technical efficiency (EC) from the formula 5, which is the contribution of the technical efficiency in the period $t$ and the period of $\mathrm{t}+1$. Then, we can see:

$\mathrm{TPF}=\mathrm{EC} \times \mathrm{TC}$ scholars have perfected it, applying it to production analysis, the change of productivity is attributed to technological change and technical efficiency change [23]. Both can be calculated by distance function. The change of productivity is to use the distance function to calculate the input and output changes during t period to $t+1$ period. Malmquist index is defined as:

Among them, the comprehensive technical efficiency (EC) indicates the change of the technical efficiency on the degree of contribution to the productivity from period $t$ to period $t+1$. EC can be divided into PE (pure technical efficiency) and SE (scale efficiency). So:

\section{$\mathrm{TPF}=\mathrm{EC} \times \mathrm{TC}=\mathrm{PE} \times \mathrm{SE} \times \mathrm{TC}$}

Among them, PE shows the impact of the level of production management changes on productivity, $\mathrm{PE}>1$ indicates that the efficiency is improved, and vice versa. SE represents the change in the efficiency of the return of the scale, $\mathrm{SE}>1$ indicates the optimal size of production, on the contrary, it indicates that it is far from optimal. TC (technological progress) indicates that the change of the production technology of the decision making unit in stage $t$ to the $t>1$ stage, TC $>1$ means that the production technology is improved, whereas the production technology is in decline.

\subsection{Evaluation Results and Their Spatial Distribution Characteristics}

Table 4. Regional eco efficiency values in Jiangxi province 2009-2013.

\begin{tabular}{|c|c|c|c|c|c|c|c|c|c|}
\hline & 2009 & & & 2010 & & & 2011 & & \\
\hline & $C^{2} R$ & $\mathrm{BC}^{2}$ & Scale & $C^{2} R$ & BC $^{2}$ & Scale & $C^{2} R$ & $\mathrm{BC}^{2}$ & Scale \\
\hline Nanchang & 0.965 & 1.000 & irs & 0.950 & 0.999 & irs & 1.000 & 1.000 & - \\
\hline Jingdezhen & 0.683 & 1.000 & irs & 0.782 & 1.000 & irs & 1.000 & 1.000 & - \\
\hline Pingxiang & 0.566 & 0.575 & irs & 0.748 & 0.762 & irs & 0.929 & 0.934 & drs \\
\hline Jiujiang & 0.715 & 0.721 & irs & 0.822 & 0.836 & irs & 0.729 & 0.738 & irs \\
\hline Xinyu & 0.690 & 0.797 & irs & 0.842 & 0.891 & irs & 0.997 & 1.000 & irs \\
\hline Ganzhou & 0.912 & 0.921 & irs & 1.000 & 1.000 & - & 1.000 & 1.000 & - \\
\hline Ji'an & 0.737 & 0.822 & irs & 0.924 & 1.000 & irs & 0.985 & 0.985 & - \\
\hline Yichun & 0.808 & 0.809 & irs & 0.930 & 0.930 & - & 0.991 & 0.991 & - \\
\hline Fuzhou & 0.715 & 1.000 & irs & 0.082 & 0.116 & irs & 1.000 & 1.000 & - \\
\hline \multirow[t]{3}{*}{ Shangrao } & 0.618 & 0.686 & irs & 0.903 & 0.913 & irs & 1.000 & 1.000 & - \\
\hline & 2012 & & & 2013 & & & \multicolumn{3}{|c|}{ Average value } \\
\hline & $C^{2} R$ & $\mathrm{BC}^{2}$ & Scale & $C^{2} R$ & $\mathrm{BC}^{2}$ & Scale & $C^{2} R$ & $\mathrm{BC}^{2}$ & Scale \\
\hline Jingdezhen & 0.991 & 1.000 & irs & 0.879 & 1.000 & irs & 0.867 & 1 & 0.991 \\
\hline Pingxiang & 1.000 & 1.000 & - & 0.937 & 0.953 & irs & 0.836 & 0.8448 & 1.000 \\
\hline Jiujiang & 0.961 & 0.967 & irs & 0.923 & 0.927 & irs & 0.83 & 0.8378 & 0.961 \\
\hline Xinyu & 1.000 & 1.000 & - & 1.000 & 1.000 & - & 0.9058 & 0.9376 & 1.000 \\
\hline Yingtan & 1.000 & 1.000 & - & 0.975 & 0.989 & irs & 0.9392 & 0.9978 & 1.000 \\
\hline Ganzhou & 1.000 & 1.000 & - & 0.902 & 0.919 & drs & 0.9628 & 0.968 & 1.000 \\
\hline Ji'an & 1.000 & 1.000 & - & 1.000 & 1.000 & - & 0.9292 & 0.9614 & 1.000 \\
\hline Yichun & 1.000 & 1.000 & - & 0.948 & 0.963 & drs & 0.9354 & 0.9386 & 1.000 \\
\hline Fuzhou & 0.997 & 1.000 & irs & 0.968 & 1.000 & irs & 0.7524 & 0.8232 & 0.997 \\
\hline Shangrao & 1.000 & 1.000 & - & 0.989 & 0.994 & irs & 0.902 & 0.9186 & 1.000 \\
\hline
\end{tabular}


Calculation of the Eco-efficiency measure of the cities in Jiangxi province by DEAP2.1, Select 11 cities in Jiangxi province from 2009 to 2013 as the object of study, they are Nanchang, Jiujiang, Jingdezhen, Pingxiang, Xinyu, Yingtan, Ganzhou, Yichun, Shangrao, Ji'an, Fuzhou. Then calculate their ecological efficiency, the results are shown in Table 4.

From table 4, the ecological efficiency of most areas in Jiangxi province is obviously low. In 2009-2013, the ecological efficiency of the cities in Jiangxi Province, that is, the pure technical efficiency of more effective cities including Nanchang, Jingdezhen, Yingtan. But in the model, the effective number of the Nanchang and Yingtan account for $18 \%$ of all cities. According to the original data, Nanchang GDP accounted for a large part of Jiangxi Province, which indicates that this area to maintain a high level of economic development in creating more economic value, while still attached great importance to the level of the city's ecological efficiency. Yingtan City of Eco-efficiency has been effective all the time, as compared with other regions both in water and industrial "three wastes" discharge are in a low level, so even if in GDP is not outstanding, it can still effectively maintain the ecological efficiency. Although we have found that the three areas of ecological efficiency, it is not difficult to find that the vast area where most of the energy consumption and industrial "three wastes" emissions is still performing at a high level, which pointed out the these areas in the rational use of resources still have greatly improved.

The ecological efficiency of the remaining cities is invalid element, that is, the input and output of resources have not reached the optimal state. Although the ecological efficiency of these regions is invalid, but its value is close to 1 , At the same time, the scale of the remuneration is increasing, which explains the reasons for the low efficiency of the scale, because of the low technical efficiency. As Jingdezhen and Fuzhou. Their pure technical efficiency is 1, but their technical efficiency is less than 1, which shows only for technical efficiency, does not need to invest the decrease and increase in output, No 1 is achieved because the scale is not matched with the input and output, which requires an increase in size or scale, Jingdezhen and Fuzhou need to increase the size, while Ganzhou and Yichun will need to reduce the size.

In the 11 region, the scale is effective in 3 cities (Nanchang, Xinyu, and Ji'an). 6 cities (Jiujiang, Jingdezhen, Pingxiang, Yingtan, Fuzhou and Shangrao) in the scale of the increase range, 2 cities (Ganzhou and Yichun) in the scale of efficiency decline range. For the pure technical efficiency is high or effective, and in the scale efficiency of the region, it should be appropriate to expand the scale, increase the output; For the scale efficiency decline range and pure technical efficiency, it should be appropriate to adjust the size of the allocation of resources for better.

For this situation, the ecological efficiency of the model is 1 , I think the reason is that the model is mainly focused on technical efficiency, and is the evaluation of the effectiveness of production technology. It may be in the production technology of Jiangxi province has been in a more advanced level, which led to a pure technical efficiency of 1 . On the other hand, this paper only set up an output indicator in setting up the evaluation index system. But the input index is seven, and the model more suitable for input and output indicators are plural, which will affect the eco-efficiency of $\mathrm{BC}^{2}$ to some extent.

\subsection{Regional Super Efficiency Analysis of Jiangxi Province}

Through the calculation of the value of the regional ecological efficiency in Jiangxi Province, we found that the ecological efficiency of several regions was 1 for many years, which could not be effectively evaluated. In order to complete the study of the ecological efficiency of 1, we are using the super efficiency DEA to study. Using DEA-SOLVER software, the research object is the 11 cities in Jiangxi Province, to calculate the level of ecological efficiency of Jiangxi province by means of calculating the level of regional or provincial level in Jiangxi province. The results are shown in Table 5.

Table 5. Super efficiency values (SE-DEA) in Jiangxi Province, 2009-2013.

\begin{tabular}{llllllll}
\hline efficiency values & $\mathbf{2 0 0 9}$ & $\mathbf{2 0 1 0}$ & $\mathbf{2 0 1 1}$ & $\mathbf{2 0 1 2}$ & $\mathbf{2 0 1 3}$ & value & Ranking \\
\hline Nanchang & 0.965 & 0.950 & 1.101 & 1.164 & 1.028 & 1.042 & 2 \\
Jingdezhen & 0.683 & 0.782 & 1.011 & 0.991 & 0.879 & 0.869 & 8 \\
Pingxiang & 0.566 & 0.748 & 0.929 & 1.062 & 0.937 & 0.848 & 9 \\
Jiujiang & 0.715 & 0.822 & 0.729 & 0.961 & 0.923 & 0.830 & 10 \\
Xinyu & 0.690 & 0.842 & 0.997 & 1.058 & 1.072 & 0.932 & 5 \\
Yingtan & 0.825 & 0.896 & 1.014 & 1.092 & 0.975 & 0.960 & 4 \\
Ganzhou & 0.912 & 1.000 & 1.037 & 1.002 & 0.902 & 0.971 & 3 \\
Ji'an & 0.737 & 0.924 & 0.985 & 1.075 & 1.008 & 0.946 & 6 \\
Yichun & 0.808 & 0.930 & 0.991 & 1.034 & 0.948 & 0.942 & 7 \\
Fuzhou & 0.715 & 0.082 & 1.004 & 0.997 & 0.968 & 0.753 & 11 \\
Shangrao & 0.618 & 0.903 & 4.053 & 1.127 & 0.989 & 1.538 & 1 \\
Average & 0.749 & 0.807 & 1.259 & 1.051 & 0.966 & & \\
\hline
\end{tabular}


According to table 5, it can be found that the time scale is analyzed, and the ecological efficiency of Jiangxi province is found to be a parabola. In 2011 and 2012, the average value of two years was more than 1 , which is because the concept of green economic production has gradually affected the development of the economy. At the beginning, the development pays more attention to the economic efficiency, but neglects the influence of the ecological environment, which leads to the low efficiency of the first two years, Along with the enhancement of people's environmental awareness and the increasing emphasis on Ecological construction in China, the economic development is more concerned about the environment. But the ecological efficiency of 2013 was lower than 1, this shows that there are problems in the development of regional economy in Jiangxi Province, which needs to be adjusted appropriately, and put forward appropriate strategies to reduce the ecological efficiency.

Take 2013 as an example, the efficiency of Nanchang, Xinyu and Ji'an City value is 1 , because CCR model evaluation of the maximum value is 1 , so the SE-DEA eco efficiency value to indicate three regional ecological efficiency, Nanchang 1.028, Xinyu is 1.072, Ji Anwei 1.008, Which means that the input elements can be increased by $1.028,1.072$ and 1.008., respectively, under the premise of ensuring the efficiency value of the same.

Vertical, the region can be classified, the ecological efficiency of the mean more than 1 of the Nanchang and Shangrao into a class, which is relatively high ecological efficiency, This shows that the development of the region is more concerned about the ecological impact, and pay more attention to the protection of the ecological. On the other hand, it will be close to 1 in Xinyu, Yingtan, Ganzhou, Ji'an and Yichun, although the average ecological efficiency of these cities has not reached 1 but is close to 1, as long as these areas in the energy saving and emission reduction efforts can achieve the goal of ecological efficiency. In addition, the ecological efficiency of Fuzhou, Pingxiang, Jiujiang and Jingdezhen is classified, which is lower than that of the 0.9 . According to the original data, we will find that the four cities in terms of industrial wastes in other areas at a higher level, especially sulfur dioxide emissions are significantly higher than in other areas. Which leads to low efficiency values for these regions. And the ecological efficiency of the four cities is a parabola, that is, after experiencing the stage of the enhancement of the ecological efficiency, it has been a new phenomenon.

\section{Dynamic Analysis of Regional Ecological Efficiency in Jiangxi Province}

\subsection{Ecological Efficiency of TPF Index Changes}

In order to analyze the dynamic change trend of eco efficiency in different regions in Jiangxi Province, we use the Malmquist index model to calculate the values of eco efficiency change. It mainly analyzes the index of regional ecological efficiency of the TPF change, calculation results are shown in Table 6 and 7.

Table 6. Changes of ecological efficiency in Jiangxi Province during 2009-2013.

\begin{tabular}{lllll}
\hline & $\mathbf{2 0 0 9 - 2 0 1 0}$ & $\mathbf{2 0 1 0 - 2 0 1 1}$ & $\mathbf{2 0 1 1 - 2 0 1 2}$ & $\mathbf{2 0 1 2 - 2 0 1 3}$ \\
\hline Nanchang & 1.02 & 1.47 & 1.043 & 0.939 \\
Jingdezhen & 1.322 & 1.471 & 1.335 & 0.933 \\
Pingxiang & 1.195 & 1.378 & 1.08 & 0.921 \\
Jiujiang & 1.281 & 1.516 & 1.311 & 0.915 \\
Xinyu & 1.398 & 1.279 & 1.122 & 1.013 \\
Yingtan & 1.479 & 1.811 & 1.101 & 0.909 \\
Ganzhou & 1.249 & 1.944 & 1.031 & 0.887 \\
Ji'an & 1.266 & 2.013 & 1.102 & 0.931 \\
Yichun & 1.307 & 2.069 & 1.11 & 0.979 \\
Fuzhou & 0.11 & 17.195 & 1.12 & 0.345 \\
Shangrao & 2.455 & 2.409 & & 0.966 \\
\hline
\end{tabular}

According to table 6, we find that each region has experienced a period of growth in the 2010-2011 years, but in the 2011-2012 stage has experienced negative growth stage, and then began to decline. The TPF index is 1 as the cut-off point, which means that more than 1 of the total factor productivity is improved, and the efficiency is decreased if less than 1. By the end of 2012, the value of TPF in all regions of Jiangxi province was more than 1, which indicates that the development of each region in Jiangxi province reached a relatively high level in the end of 2012. The TPF value of total factor productivity of Ji'an, Yichun and Fuzhou experienced a rapid growth in 2010-2011. But in the 2012-2013, all the TPF values in all regions are less than 1 except Xinyu, This shows that in this year the development of the region's lack of technical support, technological progress has dropped. However, after the reduction in 2012, Shangrao in 13 years, showing an upward trend, which shows that Shangrao will be the development of technology as an important direction of development. 
Table 7. Changes of regional ecological efficiency in Jiangxi Province during 2009-2013.

\begin{tabular}{llllll}
\hline & Technical efficiency & Technological progress & Pure technical efficiency & Scale efficiency & TFP \\
\hline $2009-2010$ & 1 & 1.28 & 1 & 1 & 1.28 \\
$2010-2011$ & 1 & 3.14 & 1 & 1 & 1 \\
$2011-2012$ & 1 & 1.06 & 1 & 1 & 1.06 \\
$2012-2013$ & 1 & 0.94 & 1 & 1 & 0.94 \\
\hline
\end{tabular}

According to table 7 , in the four period, the TPF index of each region in Jiangxi province is in the overall trend, but the overall trend is in a declining state, which shows that the level of ecological efficiency in Jiangxi province is a step backward.

The TPF index is the restriction of the technical efficiency and the technological progress. From table 7, it can be known that the technical efficiency is 1 , so that the TPF index of every region in Jiangxi province is influenced by technological progress, The more numerical value of technological progress, the greater the TPF index. On the contrary, the smaller the technological progress, the smaller the TPF exponent, So in a certain technical efficiency, it can be said that technological progress is the leading factor to promote the TPF index, but it can also be a limiting factor to hinder the improvement of TPF index.

\subsection{Redundancy Analysis of Regional Eco Efficiency in Jiangxi Province}

In 2013 as an example, the Malmquist index model was used to calculate the redundancy analysis of the input factors in the region of Jiangxi Province in 2013, as shown in Table 8.

Table 8. Jiangxi Province regional input feature redundancy analysis in 2013.

\begin{tabular}{|c|c|c|c|c|c|c|c|c|}
\hline DMU & & $\begin{array}{l}\text { Total water } \\
\text { consumption }\end{array}$ & $\begin{array}{l}\text { Construction } \\
\text { land area }\end{array}$ & $\begin{array}{l}\text { Number of } \\
\text { employees }\end{array}$ & $\begin{array}{l}\text { Fixed asset } \\
\text { investment }\end{array}$ & $\begin{array}{l}\text { Wastewater } \\
\text { emissions }\end{array}$ & $\mathrm{SO}_{2}$ emissions & $\begin{array}{l}\text { Solid waste } \\
\text { emissions }\end{array}$ \\
\hline \multirow{2}{*}{ Nanchang } & Redundancy & 0 & 0 & 0 & 0 & 0 & 0 & 0 \\
\hline & rate & 0 & 0 & 0 & 0 & 0 & 0 & 0 \\
\hline \multirow{2}{*}{ Jingdezhen } & Redundancy & 0 & 0 & 0 & 0 & 0 & 0 & 0 \\
\hline & rate & 0 & 0 & 0 & 0 & 0 & 0 & 0 \\
\hline \multirow{2}{*}{ Pingxiang } & Redundancy & 0 & -2.51 & 0 & -1777432.33 & -645.07 & -31448.68 & 0 \\
\hline & rate & 0 & $5.00 \%$ & 0 & $21.49 \%$ & $2.50 \%$ & $34.92 \%$ & 0 \\
\hline \multirow{2}{*}{ Jiujiang } & Redundancy & -2.38 & 0 & -15.41 & -2428379.43 & 0 & -47767.06 & 0 \\
\hline & rate & $9.06 \%$ & 0 & $14.00 \%$ & $16.11 \%$ & 0 & $50.91 \%$ & 0 \\
\hline \multirow{2}{*}{ Xinyu } & Redundancy & 0 & 0 & 0 & 0 & 0 & 0 & 0 \\
\hline & rate & 0 & 0 & 0 & 0 & 0 & 0 & 0 \\
\hline \multirow{2}{*}{ Yingtan } & Redundancy & -1.10 & -0.48 & -0.47 & -607246.95 & 0 & 0 & -11.72 \\
\hline & rate & $13.92 \%$ & $1.77 \%$ & $1.49 \%$ & $15.41 \%$ & 0 & 0 & $3.20 \%$ \\
\hline \multirow{2}{*}{ Ganzhou } & Redundancy & -2.48 & 0 & -6.21 & -196082.78 & -588.80 & 0 & 0 \\
\hline & rate & $6.90 \%$ & 0 & $5.23 \%$ & $1.47 \%$ & $1.23 \%$ & 0 & 0 \\
\hline \multirow{2}{*}{ Ji'an } & Redundancy & 0 & 0 & 0 & 0 & 0 & 0 & 0 \\
\hline & rate & 0 & 0 & 0 & 0 & 0 & 0 & 0 \\
\hline \multirow{2}{*}{ Yichun } & Redundancy & -7.45 & 0 & -2.181 & -1262113.77 & -636.25 & 0 & 0 \\
\hline & rate & $16.51 \%$ & 0 & $2.24 \%$ & $11.22 \%$ & $1.60 \%$ & 0 & 0 \\
\hline \multirow{2}{*}{ Fuzhou } & Redundancy & 0 & 0 & 0 & 0 & 0 & 0 & 0 \\
\hline & rate & 0 & 0 & 0 & 0 & 0 & 0 & 0 \\
\hline \multirow{2}{*}{ Shangrao } & Redundancy & -5.47 & 0 & -3.67 & -1634101.27 & -600.66 & 0 & -522.39 \\
\hline & rate & $17.01 \%$ & 0 & $3.71 \%$ & $14.03 \%$ & $1.62 \%$ & 0 & $10.23 \%$ \\
\hline
\end{tabular}

The analysis of regional input output in Jiangxi province in 2013 , according to table 8 . despite the various cities in the index of the input redundancy situation is vastly different, but it is not difficult to find redundant mainly concentrated in the four aspects of the total water use, employees, fixed assets investment and waste water emissions. Such as fixed asset investment in Pingxiang, the redundancy rate is $21.49 \%$, the total water consumption in Shangrao is $17.1 \%$, the $\mathrm{SO}_{2}$ emissions in Jiujiang is $50.91 \%$. The reason of redundancy analysis, is to pass to adjust the input factors to achieve ecological efficiency for this purpose.

Pingxiang is mainly to solve the adjustment of investment in fixed assets and $\mathrm{SO}_{2}$ emissions of two input elements, the redundancy rate respectively $21.49 \%$ and $34.92 \%$, which 
shows Pingxiang in the investment in fixed assets and sulfur dioxide emissions with the local economic development uncoordinated, and need to be adjusted to achieve ecological efficiency.

Seven input indicators in Jiujiang have four indicators need to be adjusted, the total water consumption is reduced by 337.8 million cubic meters, the staff of 154.05 thousand people, fixed asset investment decreased by 24.283 billion yuan. At the same time, reduction of 47767 tons of sulfur dioxide emissions, the reduce proportion of $9.06 \%, 14 \%$, $16.11 \%$ and $50.91 \%$ respectively. But Jiujiang should focus on sulfur dioxide emissions, because it needs to reduce the magnitude of as high as $50.91 \%$, it is still in a weak position in the treatment of sulfur dioxide emissions, if we can increase the disposal of waste gas, reduce emissions, and the ecological efficiency of Jiujiang will become effective.

\section{Conclusions and Policy Recommendations}

Analysis of ecological efficiency of 11 cities in Jiangxi province by DEA method. At the same time, using SE-DEA to sort the ecological efficiency of 1 , and finally using Malmquist index to evaluate the dynamic situation of the regional ecological efficiency. The results shows like that:

(1) in the 2009-2013, the ecological efficiency of the cities in Jiangxi province is relatively low, This five years in an effective state of the city does not exist, the ecological efficiency of four cities in Nanchang, Pingxiang, Xinyu and Ji'an has been in the rising stage, and finally reached the effective state.

(2) through the analysis of the super efficiency DEA, the ecological efficiency of each city is not obvious, the highest in Shangrao is 1.538, while the lowest in Fuzhou area is 0.753 , the difference is 2 times.

(3) Through the analysis of the total factor production efficiency of each region, the region in Jiangxi province has experienced a growth phase, at present, the growth rate is in a downward trend.

(4) Various cities in the index of the input redundancy situation is vastly different, but it is not difficult to find redundant mainly concentrated in the four aspects of the total water use, employees, fixed assets investment and waste water emissions.

The following policy recommendations can be obtained from the results of the study:

(1) actively take the initiative to change the mode of economic development, promote the upgrading of the industrial structure, change the parts of "resource of high investment, low utilization and high emissions" extensive mode of production, under the drive of the transformation of the structure improved allocation of resources effect.

(2) Through strengthening the links of each region to achieve the effective sharing of resources, through regional cooperation strategy to jointly develop the resource conservation and utilization. For example, Nanchang as an effective area, can realize the impact of the surrounding area through its own regional influence, to promote the overall efficiency of the upgrade.

(3) Some regional investment structure is irrational, and the benefit is not high, we should increase the investment in fixed assets, and actively guide the effective use of foreign investment in the region, we should also prevent blind investment.

(4) Increasing investment in education, improving the quality of population and the level of science and technology. The amount of human resources will directly affect the regional development and technological progress, and ultimately affect the level of ecological efficiency. In some areas, the high efficiency of the ecological efficiency is often accompanied by the good scientific educational institutions and the abundant human capital.

(5) Strengthen environmental pollution management, and form a long-term mechanism for environmental protection. Environmental pollution control should be left to the market more choices, the establishment of emission trading market, the implementation of emission trading system, to play the role of "seed" of public finance and guide social capital into the field of ecological construction and environmental protection.

(6) Strengthen environmental governance capacity building. To strengthen the monitoring network, forecast and early warning, emergency management and other facilities and public platform construction, support related fields of technology development and Application.

(7) Strengthen the protection of the environment, sustainable development and other propaganda and science, improve the ability and level of public participation in ecological environment protection.

The improvement of the level of ecological efficiency is a systematic project, we should consider from many angles and all directions. While trying to develop the economy in Jiangxi Province, we should pay more attention to the coordination of resource investment and environmental impact. Using sustainable development strategy as the guiding ideology of economic development, coordinate the relationship between economic, environment and resources. In achieving economic goals, to create a resource-saving and environment-friendly society, and to achieve the greatest social and environmental benefits.

\section{Acknowledgments}

This work was supported by grants from the National Natural Science Foundation of China (No. 21407069/41001376/21367013/41161064) and the Colleges and Universities Humanities and Social Science Research Project in jiangxi Province (No. 2013GL1313). 


\section{References}

[1] SCHALTEGGER S, STURM A. Ökologische rationalität-an-satzpunkte zur ausgestaltung von ökologieorientierten Management Instrumenten [J]. Die Untemehmung, 1990 (4): 273-290.

[2] WBCSD. Eco-efficiency: Leadership for improved economic and environmental performance [M]. Geneva: WBCSD, 1996: $3-16$.

[3] Ullah, A., Perret, S. R., Gheewala, S. H., \& Soni, P. Eco-efficiency of cotton-cropping systems in Pakistan: an integrated approach of life cycle assessment and data envelopment analysis [J]. Journal of Cleaner Production. 2016, (1): 31-38. doi: 10.1016/j.jclepro.2015.10.112.

[4] Iribarren, D., Marvuglia, A., Hild, P., Guiton, M., Popovici, E., \& Benetto, E. Life cycle assessment and data envelopment analysis approach for the selection of building components according to their environmental impact efficiency: a case study for external walls[J]. Journal of Cleaner Production, 2015, 87, 707-716. doi: 10.1016/j.jclepro.2014.10.073.

[5] Iribarren, D., Martín-Gamboa, M., O’Mahony, T., \& Dufour, J. Screening of socio-economic indicators for sustainability assessment: a combined life cycle assessment and data envelopment analysis approach [J]. The International Journal of Life Cycle Assessment, 2016, 21(2), 202-214. doi: 10.1007/s11367-015-1002-8.

[6] Mahdiloo, M., Saen, R. F., \& Lee, K. H. Technical, environmental and eco-efficiency measurement for supplier selection: An extension and application of data envelopment analysis [J]. International Journal of Production Economics, 2015, 168, 279-289. doi: 10.1016/j.ijpe.2015.07.010.

[7] Ewertowska, A., Galán-Martín, A., Guillén-Gosálbez, G., Gavaldá, J., \& Jiménez, L. Assessment of the environmental efficiency of the electricity mix of the top European economies via data envelopment analysis [J]. Journal of Cleaner Production. 2015, 11, 102-114. doi: 10.1016/j.jclepro.2015.11.100.

[8] HANG Bing, HUANG He Ping, BI Jun. Material flow analysis and data envelopment analysis based regional eco-efficiency analysis: case study of Jiangsu Province [J]. Acta Ecological Science, 2009, 29(5): 2473-2480.

[9] Biji Kurup, William Altham, Rvan Berkel Triple bottom line accounting applied for industrial symbiosis [C]. Sydney: ALCAS conference, 2005.

[10] Helge Bratteb, Ole Jorgen Hanseen. Productivity2005 research plan P-2005 industrial ecology [C]. Norway: Norwegian University of Science and Technology industrial ecology programmer, 2005.

[11] Michelsen O, Fet A M, Dahlsrud A. Eco-efficiency in extended supply chains: a case study of furniture production [J]. Journal of Environmental Management, 2006, 79(3): 290-297.

[12] K Rine. Industrial implementation of extended producer responsibility in an industrial ecology perspective [D] Norway: Norwegian University of Science and Technology, 2005.

[13] Van Caneghem J, Block C, Cramm P, Mortier R, Vandecasteele C. Improving eco-efficiency in the steel industry: the Arcelor Mittal Gent case [J]. Journal of Cleaner Production, 2010, 18(8): 807-817.

[14] Jingru Liu. The compound eco efficiency of eco industrial park and the evaluation index system of [J]. ecology journal, 2014, 34(1): 136-141.

[15] Chaona Li. The construction and application of environmental performance evaluation index system of eco industrial demonstration park [D]. Ji'nan: Shandong University, 2014.

[16] Lin Ma. Research on comprehensive evaluation of national industrial park in Nanchang province [D]. Jiangxi: Jiangxi University of Finance and Economics, 2013.

[17] Na Zhang. Evaluation of eco industrial park based on complex eco efficiency [D]. Nanjing: Nanjing Agricultural University, 2013.

[18] Jiating Wang. Eco efficiency evaluation of eco industrial parks in China $[\mathrm{J}]$. contemporary economic management, 2013, 35(7): 41-46.

[19] Chanjuan Xiao. Evaluating the eco efficiency of eco industrial park in Tianjin TEDA eco industrial park as an example [J]. Journal of Tianjin University of Commerce, 2009 (1): 26-30.

[20] Sun Xiaomei. Study on the evaluation index system of operational efficiency of eco industrial parks [J]. China population, resources and environment, 2010, 20(1): 124-129.

[21] Charnes A, Cooper W W, Rhodes E. Measuring the efficiency of decision making units [J]. European Journal of Operational Research, 1978, 2(6): 429-444.

[22] Anersen P, Petersen N C. A procedure for ranking efficient unit in data envelopment analysis [J]. Management Science, 1993, (10): 1261-1264.

[23] Fare R S, Grosskopf S, Norris M. Productivity growth, technical progress and efficiency change in industrialized countries [J]. American Economic Review, 1994, 84(1): 66-83. 